\title{
Effect of Microenvironment on Species Distribution Patterns in the Regeneration Layer of Forest Gaps and Non-Gaps in a Subtropical Natural Forest, China
}

\author{
Zhongsheng He ${ }^{1,2,3}{ }^{-}$, Lijing Wang ${ }^{1}$, Lan Jiang ${ }^{1,2,3}$, Zhe Wang ${ }^{1,2,3}$, Jinfu Liu ${ }^{1,2,3, *}$, \\ Daowei $\mathrm{Xu}{ }^{1,2,3}$ and Wei Hong ${ }^{1,2,3}$ \\ 1 College of Forestry, Fujian Agriculture and Forestry University, Fuzhou 350002, Fujian, China; \\ jxhzs85@fafu.edu.cn (Z.H.); wanglijingcas@163.com (L.W.); Jln0629@183.com (L.J.); sxwz93@126.com (Z.W.); \\ xudaowei2004446@126.com (D.X.); fjhongwei@126.com (W.H.) \\ 2 Key Lab of Ecology and Resources Statistics of Fujian Colleges, Fuzhou 350002, Fujian, China \\ 3 Cross-Strait Nature Research Center of Fujian Agriculture and Forestry University, \\ Fuzhou 350002, Fujian, China \\ * Correspondence: fjlif@fafu.edu.cn; Tel.: +86-1535-911-9967
}

Received: 3 December 2018; Accepted: 13 January 2019; Published: 24 January 2019

check for updates

\begin{abstract}
The aim of this study was to explore the effect of gap environmental factors on the plant population regeneration pattern in the Castanopsis kawakamii natural forest. We used the detrended canonical correspondence analysis (DCCA) method to study coupling relationships between species distribution in the regeneration layer and environmental factors. The results showed that: (1) The main environmental factors that influenced species distribution in the forest gaps and non-gaps were different, and the highest explanation rate of environmental factors was the soil temperature below the surface $10 \mathrm{~cm}$ (ST10); (2) The relationships between species distribution in the regeneration layer of the forest gaps and non-gaps were mainly restricted by environmental factors, given the environmental factors complied with the ecological niche hypothesis; and (3) For the endangered C. kawakamii population, there were positive and negative relationships between the environmental factors and the various species in the forest gaps and non-gaps, whilst the effects of such relationships were varied. Some management operations, including the creation of artificial gaps and adequate fertilization in the non-gaps, could more effectively promote the growth and regeneration of the C. kawakamii population.
\end{abstract}

Keywords: Castanopsis kawakamii natural forest; detrended canonical correspondence analysis (DCCA); environmental factors; forest gaps and non-gaps; plant regeneration

\section{Introduction}

Forest gaps are an important interference to forests [1], where gap disturbance influences species coexistence in the forest community and biodiversity maintenance, which is an important process of forest regeneration and succession [2]. Gap disturbance promotes variations in micro-environmental conditions, including solar radiation, air temperature, relative humidity, soil temperature, and soil physical and chemical properties, which makes it a mechanism for determining species distribution patterns [3,4]. After gap formation, microenvironment heterogeneity plays a role in the selection of plant composition, seed germination, and seedlings recruitment [3-5]. This can be recognized as an essential driving factor for the dynamic balance in long-term forest succession [6], i.e., gap age, edaphic factors, environmental factors, and gap border trees could directly or indirectly affect the species density and adaptability [7-9]. However, the quantitative relationship between plants and 
environmental factors is not revealed in these studies; therefore, the maintenance mechanism between species coexistence and the environment is still not clear and requires further study.

Quantitative classification could objectively explain the relationships between plant distribution patterns and communities in relation to environmental factors [10]. The analysis and study of the relationship between plants and the environment involves the explanation of vegetation type by climate, which is important to the development of theory and practice [11]. Additionally, a detrended canonical correspondence analysis (DCCA) can potentially avoid the arch effect and connect plants and sample sorting plots with the role of multiple factors to make the relationship between vegetation characteristics and factors more obvious in a sequence diagram [12]. The method has become a popular method of vegetation gradient analysis and environmental interpretation, and it has gained wide application in the northern rangelands of the Isfahan Province (Iran) [13], the tropical and subtropical forests in the Gobind Sagar Reservoir in India [14], the orchard community in China [10], and the karst woody vegetation in China [15]. However, the related studies have not explicitly focused on the contribution of environmental factors to community composition. Therefore, the key to studying the maintenance mechanism between vegetation and the environment is understanding how to quantify the relationship between environmental factors and community composition.

Castanopsis kawakamii Hayata is an endemic evergreen broad-leaved endangered tree species of Fagaceae found in the subtropical southern area of China, and this forest has been the subject of several prior works [3,4,16-19]. Interference patterns, species diversity, and edge effects of forest gaps were studied in the C. kawakamii natural forest $[16,17]$. In addition, the regeneration process, including the heterogeneity of environmental factors, species competition, the regeneration niche, and community stability in the forest gaps, was also studied $[3,17,18]$. These prior studies revealed that forest gaps developed heterogeneity in environmental factors, promoted seedlings regeneration and settlement, and improved seedling competition intensity and niche width in forest gaps. However, we still do not understand how environmental factors affect the species distribution pattern in forest gap regeneration, which limits the practical measures in the conservation action of $C$. kawakamii seedlings in the C. kawakamii natural forest.

The study of the coupling relationship between forest gap regeneration layer communities and environmental factors in the C. kawakamii natural forest was aimed at answering three questions: (1) Which factors (e.g., light intensity, air temperature and humidity, soil temperature, and soil properties, etc.) affect the distribution patterns of community regeneration layers, and how do we select them? (2) How do we quantitatively analyze the factors that influence the distribution pattern of the regeneration layer species? (3) How do we explain plant regeneration under conditions of changing environmental factors in forest gaps and non-gaps? In doing so, some specific measures could provide to protect the C. kawakamii species, with the aim of strengthening the scientific management and reasonable protection of the C. kawakamii natural forest.

\section{Materials and Methods}

\subsection{Study Site and Stand History}

The study site was located in the C. kawakamii Nature Reserve (latitude $26^{\circ} 07^{\prime}-26^{\circ} 12^{\prime} \mathrm{N}$, longitude $117^{\circ} 24^{\prime}-117^{\circ} 29^{\prime} \mathrm{E}$ ) in the middle of the subtropical region of China (Figure 1 ). The altitude varied between 180 and $604 \mathrm{~m}$. The study site has a subtropical monsoon climate with an average annual temperature of $19.5^{\circ} \mathrm{C}$. The average annual precipitation is about $1500 \mathrm{~mm}$, along with average annual relative humidity and wind speed of $79 \%$ and $1.6 \mathrm{~m} / \mathrm{s}$, respectively. The soil type in this forest mainly consists of ferric acrisols with abundant humus, which is rich in soil nutrition. The forest type is a subtropical evergreen broad-leaved forest. This forest is dominated by a C. kawakamii population covering an area of 700 hectares, which is known as the World C. kawakamii Forest. The main species consists of C. kawakamii, C. carlesii, Pinus massoniana, and Schima superba in the tree layer, followed by 
Litsea subcoriacea, Syzygium buxifolium, and Antidesma japonicum in the shrub layer, and Woodwardia japonica, Dicranopteris linearis, and Alpinia oblongifolia in the herb layer [3].

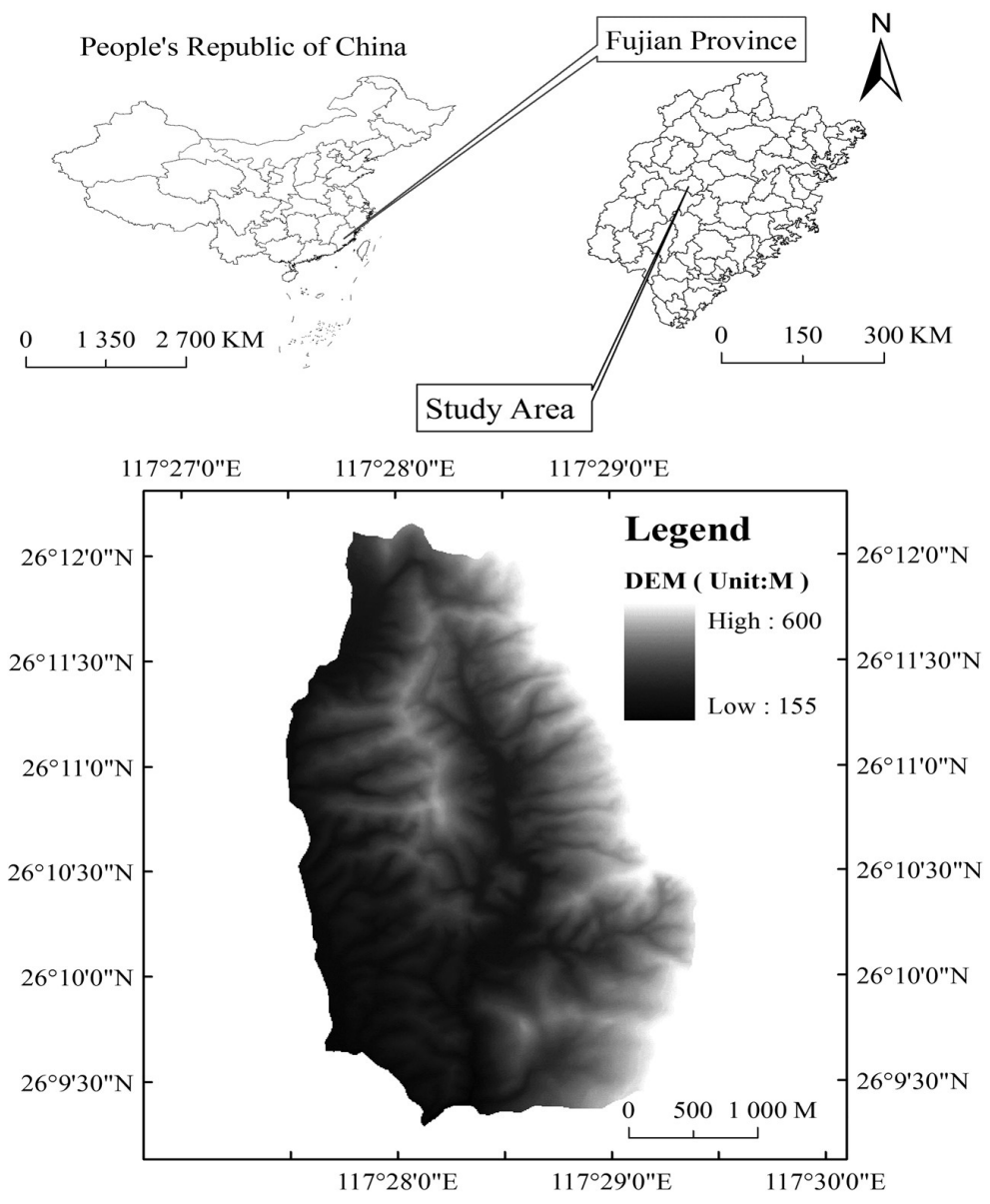

Figure 1. Shows a map of the sampling locations used in this study. The area of the Castanopsis kawakamii Nature Reserve is above 700 hectares, and the plant species composition is dominated by a mature C. kawakamii population where its age is around 100 years [3].

\subsection{Community Survey in the Regeneration Layer}

Based on a previous survey in 2003 of forest gaps using the sample line method [16], we chose 12 forest gaps and 12 non-gaps to be surveyed again in 2008 and 2013. The forest gaps were generally of an oval or irregular polygon shape. By calculating the area of each forest gap, the average area of the forest gaps was $61.89 \mathrm{~m}^{2}$, with a partial crown rate from 0.5 to 0.8 [18]. We set up three $5 \mathrm{~m} \times 5 \mathrm{~m}$ sample plots in each forest gap, and another three $5 \mathrm{~m} \times 5 \mathrm{~m}$ sample plots away from the edge of each forest gap for $10 \mathrm{~m}$ as the sample plots of non-gaps to investigate the species composition and growth characteristics. The plot areas of the forest gaps and non-gaps that we surveyed were $900 \mathrm{~m}^{2}$ each. We recorded the main biometrical characteristics in the regeneration layer of the tree layer (i.e., tree height above $3 \mathrm{~m}$ ) and shrub layer (i.e., tree height below $3 \mathrm{~m}$ ), which included tree species, individual number, height, diameter at breast height, and crown breadth. Based on the biometrical characteristics, we calculated the distribution density, abundance, dominance, and importance values of each species in the forest gaps and non-gaps using quantitative ecology methods as described in Reference [20].

\subsection{Study of Microenvironments in the Forest Gaps and Non-Gaps}

In the forest gap and non-gap sample plots, we set two sample observation perpendicular lines through the forest gap central point along the south-north and east-west directions, and we marked five observation points in the forest gap center, canopy gap edge, and the expanded gap edge and 
non-gaps. Subsequently, the climatic factors, including light intensity (LI), air temperature (AT), relative humidity above the surface of $1.5 \mathrm{~m}(\mathrm{AH})$, soil surface temperature (ST0), soil temperature below the surface $5 \mathrm{~cm}$ (ST5), soil temperature below the surface $10 \mathrm{~cm}$ (ST10), and soil water content (SWC) in the four seasons, were measured for 24 to 48 days between 2009 and 2010. These climate factors were measured hourly from 8:00 am to 6:00 pm during sunny days; then we put the average of the forest gap center, canopy gap, and expanded gap data as the values of the forest gap climatic factors, whilst the averaged four directions' data in non-gaps were used as the values of the non-gap climatic factors. Climatic factors were measured using TES-1360A handheld digital thermo-hygrometers, a 6300 needle soil thermometer, and TZS-IIW soil moisture and temperature measuring instruments. Moreover, three soil layers from the surface to $30 \mathrm{~cm}$ of the soil samples were collected by digging the soil profile, where we took $200 \mathrm{~cm}^{3}$ of soil core and soil samples back to the laboratory with three replicates. Meanwhile, non-gap soil samples, which were $10 \mathrm{~m}$ away from the edges of forest gaps, were set as the control groups. The physical and chemical properties of the soil samples were measured using the forest soil analysis method described in Reference [21]. We measured the soil's physical properties, which included soil bulk density (SBD), soil water mass content (SWMC), soil volumetric moisture content (SVMC), maximum moisture capacity (MMC), capillary water capacity (CWC), minimum water-holding capacity (MWC), non-capillary porosity (NCP), capillary porosity (CP), soil total porosity (STP), and soil aeration porosity (SAP). Meanwhile, soil chemical properties were tested, including the $\mathrm{pH}$ value $(\mathrm{pH})$, total nitrogen $(\mathrm{TN})$, hydrolysable nitrogen $(\mathrm{HN})$, total phosphorus (TP), available phosphorus (AP), total potassium (TK), available potassium (AK), soil organic matter (SOM), soil organic carbon (SOC), and $\mathrm{C} / \mathrm{N}$ ratio.

\subsection{Coupling Analysis Method}

DCCA can illustrate the relationship between vegetation patterns and environmental factors more intuitively in the ordination diagram [22,23] by connecting the plant species or sample orders with the function of the environmental variables. Previously, the selection of the main factors to analyze the qualitative and quantitative relationships between the main species and impact factors was an issue. Therefore, the Monte Carlo test was applied to demonstrate the single factor explanation rate and its significant test result. According the simple effects option of the Canoco 5.0 software, the interpretation of each single environmental factor was calculated, and then the conditional effects option was used to analyze the increasing explanation rate after continuously adding environmental factors according to the orders of the explanation rate; finally, the main factors were selected as described in Reference [24]. We used DCCA to analyze the relationship between plant species or sample plots and the environmental factors after selection of some high explanation rates for these factors. Meanwhile, the length of each factor and the angle between the factors and species were recorded. After taking the length of the factors multiplied by the cosine of the angle, the values of the coupling relationships between the main species and the environmental factors were calculated, and then analyzed the effect of environmental factors on the plant species distribution pattern. All statistical tests were conducted in Excel 2010 and Canoco 5.0 as in Reference [25].

\section{Results}

\subsection{Community Characteristics of the Regeneration Layer in Different Habitats}

The numbers of species in the regeneration layer of forest gaps and non-gaps were 88 and 79, respectively (Tables 1 and 2). The species of Ardisia punctata, Castanopsis kawakamii, Diplospora dubia, Litsea subcoriacea, Machilus grijsii, and Symplocos lancifolia were the dominant species in 12 gaps. Moreover, the species of $L$. subcoriacea was the constructive species in these gaps, whilst the importance values (IVs) of the Calamus thysanolepis species were the highest in gap 1, 5, and 6 (Table 1). Meanwhile, the IVs of Ardisia punctata species were the highest in the non-gap 1,2,3, and 8 and the IVs of Calamus thysanolepis species were the highest in the non-gap 5, 6, 7, and 12. In the non-gap 9, the IVs of 
Litsea subcoriacea species were the highest (Table 2). Microenvironment heterogeneity in the forest gaps determined the distribution and composition of plant species. According to the importance values of each species and the species competition intensity with $C$. kawakamii in the forest gaps and non-gaps [18], the main species were chosen to analyze the relationship between the species regeneration pattern and the environmental factors. By selecting the main species that had relatively high importance values and strong competition with C. kawakamii, the species of C. kawakamii, Diplospora dubia, Symplocos lancifolia, Litsea subcoriacea, and Machilus grijsii were distributed in each sample plot of the forest gaps, while Sarcandra glabra, C. kawakamii, D. dubia, L. subcoriacea, and Antidesma japonicum were distributed in each sample plot of the non-gaps.

Table 1. The importance values of the main species in the regeneration layer of forest gaps.

\begin{tabular}{ccccccccccccc}
\hline & GAP1 & GAP2 & GAP3 & GAP4 & GAP5 & GAP6 & GAP7 & GAP8 & GAP9 & GAP10 & GAP11 GAP12 \\
\hline Aja & 0.015 & 0.007 & 0.022 & 0 & 0.015 & 0.046 & 0.046 & 0.031 & 0.016 & 0.015 & 0.157 & 0 \\
Apu & 0.012 & 0.194 & 0.088 & 0.101 & 0.012 & 0.032 & 0.010 & 0.071 & 0.053 & 0.020 & 0.074 & 0.007 \\
Cfa & 0.012 & 0 & 0.048 & 0.018 & 0.012 & 0.024 & 0.022 & 0 & 0.009 & 0.005 & 0.028 & 0 \\
Cka & 0.041 & 0.065 & 0.065 & 0.088 & 0.018 & 0.024 & 0.058 & 0.053 & 0.006 & 0.005 & 0.035 & 0.038 \\
Coc & 0.027 & 0.015 & 0.006 & 0.005 & 0.027 & 0.028 & 0.078 & 0 & 0.026 & 0.014 & 0.003 & 0 \\
Cth & 0.375 & 0 & 0 & 0 & 0.375 & 0.127 & 0.092 & 0 & 0.047 & 0.040 & 0.010 & 0 \\
Ddu & 0.102 & 0.023 & 0.020 & 0.005 & 0.037 & 0.020 & 0.006 & 0.140 & 0.043 & 0.043 & 0.022 & 0.067 \\
Fol & 0 & 0 & 0 & 0 & 0.015 & 0 & 0 & 0 & 0.013 & 0.246 & 0.039 & 0.003 \\
Ich & 0 & 0.071 & 0.020 & 0.010 & 0 & 0 & 0 & 0.081 & 0.048 & 0.009 & 0.015 & 0 \\
Lsu & 0.082 & 0.121 & 0.127 & 0.088 & 0.148 & 0.094 & 0.086 & 0.050 & 0.300 & 0.116 & 0.127 & 0.117 \\
Mgr & 0.011 & 0.056 & 0.064 & 0.021 & 0.011 & 0.010 & 0.024 & 0.086 & 0.002 & 0.011 & 0.051 & 0.015 \\
Phi & 0 & 0.147 & 0 & 0 & 0 & 0.005 & 0 & 0.024 & 0.002 & 0 & 0 & 0 \\
Rco & 0 & 0.023 & 0.019 & 0 & 0 & 0.029 & 0.005 & 0.033 & 0.008 & 0.035 & 0.063 & 0 \\
Sbu & 0 & 0 & 0.028 & 0.067 & 0.020 & 0.053 & 0.169 & 0.014 & 0.033 & 0.078 & 0.020 & 0.063 \\
Sgr & 0 & 0.031 & 0.006 & 0.005 & 0 & 0 & 0.025 & 0.046 & 0.006 & 0.003 & 0.004 & 0 \\
Sla & 0.104 & 0.051 & 0.029 & 0.013 & 0.016 & 0.005 & 0.007 & 0.035 & 0.029 & 0.069 & 0.043 & 0.026 \\
Ssu & 0 & 0.050 & 0.056 & 0.024 & 0 & 0.009 & 0.034 & 0.008 & 0.028 & 0.003 & 0.003 & 0 \\
\hline
\end{tabular}

Abbreviations: Antidesma japonicum-Aja, Ardisia punctata-Apu, Castanopsis fargesii-Cfa, Castanopsis kawakamii-Cka, Camellia octopetala-Coc, Calamus thysanolepis-Cth, Diplospora dubia-Ddu, Engelhardtia fenzelii-Efe, Fissistigma oldhamii-Fol, Itea chinensis var oblonga-Ich, Litsea subcoriacea-Lsu, Machilus grijsii-Mgr, Photinia hirsuta-Phi, Randia cochinchinensis-Rco, Syzygium buxifolium-Sbu, Syzygium grijsii-Sgr, Symplocos lancifolia-Sla, Schima superba-Ssu, the same below.

Table 2. The important values of main species in the regeneration layers of non-gaps.

\begin{tabular}{ccccccccccccc}
\hline & NG1 & NG2 & NG3 & NG4 & NG5 & NG6 & NG7 & NG8 & NG9 & NG10 & NG11 & NG12 \\
\hline Aja & 0.030 & 0.050 & 0.004 & 0.005 & 0.017 & 0.041 & 0.075 & 0.010 & 0.012 & 0.020 & 0.026 & 0.034 \\
Apu & 0.216 & 0.246 & 0.096 & 0.035 & 0.006 & 0.062 & 0.014 & 0.153 & 0.106 & 0.077 & 0.040 & 0.111 \\
Cfa & 0 & 0.014 & 0.021 & 0.028 & 0.006 & 0.005 & 0.005 & 0 & 0.008 & 0.039 & 0.059 & 0.007 \\
Cka & 0.060 & 0.049 & 0.009 & 0.030 & 0.003 & 0.031 & 0.009 & 0.019 & 0.014 & 0.047 & 0.088 & 0.021 \\
Coc & 0 & 0 & 0.015 & 0.046 & 0.012 & 0.036 & 0.139 & 0 & 0 & 0 & 0.103 & 0.008 \\
Cth & 0 & 0 & 0 & 0.041 & 0.329 & 0.108 & 0.168 & 0.004 & 0.042 & 0.015 & 0 & 0.131 \\
Ddu & 0.038 & 0.035 & 0.013 & 0.116 & 0.003 & 0.019 & 0.009 & 0.114 & 0.031 & 0.130 & 0.016 & 0.016 \\
Ich & 0.029 & 0.035 & 0.072 & 0 & 0 & 0 & 0 & 0.019 & 0.173 & 0 & 0.082 & 0.081 \\
Lsu & 0.140 & 0.081 & 0.082 & 0.024 & 0.258 & 0.102 & 0.091 & 0.037 & 0.252 & 0.113 & 0.084 & 0.090 \\
Mgr & 0.119 & 0.010 & 0.081 & 0.012 & 0 & 0.013 & 0.033 & 0.044 & 0.021 & 0.064 & 0.035 & 0.020 \\
Mja & 0 & 0 & 0 & 0.008 & 0.082 & 0.138 & 0.074 & 0 & 0.006 & 0 & 0.112 & 0.128 \\
Nca & 0.005 & 0 & 0 & 0 & 0 & 0.008 & 0.023 & 0 & 0.069 & 0.045 & 0 & 0.030 \\
Sbu & 0 & 0 & 0.008 & 0.083 & 0.006 & 0.033 & 0.060 & 0.004 & 0.007 & 0.177 & 0.036 & 0.071 \\
Sgl & 0.143 & 0.016 & 0.021 & 0.004 & 0.018 & 0.030 & 0.014 & 0.068 & 0.034 & 0.031 & 0.008 & 0.014 \\
Sgr & 0.006 & 0.058 & 0.026 & 0 & 0.003 & 0.010 & 0.007 & 0.018 & 0.024 & 0.007 & 0 & 0 \\
Sla & 0.026 & 0 & 0.021 & 0.024 & 0.009 & 0.018 & 0.013 & 0.017 & 0.015 & 0.007 & 0.016 & 0.058 \\
Ssu & 0.006 & 0.135 & 0.046 & 0.014 & 0 & 0.029 & 0.012 & 0.016 & 0.014 & 0.004 & 0 & 0.017 \\
\hline
\end{tabular}

Abbreviations: non gaps-NG, Maesa japonica-Mja, Neolitsea cambodiana var glabra-Nca, Sarcandra glabra-Sgl. 


\subsection{Screening of Environmental Factors in Different Habitats}

By calculating the interpretation of the restricted sequence analysis for each environmental factor, the explanation rates of each were varied (Table 3). The highest explanation rate of a factor in the forest gaps and non-gaps was the ST10, which accounted for $16.2 \%$ and $33.6 \%$, respectively. The other explanation rates of factors were gradually decreasing in the forest gaps and non-gaps, while the explanation rates and precision of the first eleven single factors in the non-gaps were relatively higher than those in the forest gaps. The explanation rate of soil chemical properties factors was higher than those of soil physical properties in the non-gaps, while there was not obvious difference in the forest gaps.

Table 3. Screening of explanation variables of environmental factors in the forest gaps and non-gaps.

\begin{tabular}{|c|c|c|c|c|c|c|c|}
\hline Gap & Explains \% & Gap & Explains \% & Non-Gap & Explains \% & Non-Gap & Explains \% \\
\hline ST10 & 16.2 & SOC & 8.6 & ST10 & 33.6 & CWC & 6.5 \\
\hline ST5 & 15.6 & SWMC & 7.9 & $\mathrm{AT}$ & 32.6 & MMC & 6.4 \\
\hline $\mathrm{AP}$ & 15.4 & MWC & 7.9 & ST5 & 27.8 & $\mathrm{pH}$ & 5.6 \\
\hline LI & 13.0 & AK & 7.4 & ST0 & 26.8 & $\mathrm{TN}$ & 5.2 \\
\hline $\mathrm{AT}$ & 12.4 & SBD & 7.3 & $\mathrm{AP}$ & 21.1 & $\mathrm{CP}$ & 5.1 \\
\hline $\mathrm{HN}$ & 12.3 & TK & 6.7 & LI & 20.6 & $\mathrm{TP}$ & 4.5 \\
\hline ST0 & 12.1 & MMC & 6.3 & $\mathrm{C} / \mathrm{N}$ & 15.8 & SWMC & 4.3 \\
\hline $\mathrm{CP}$ & 11.2 & $\mathrm{~N} / \mathrm{CP}$ & 5.7 & SOC & 15.6 & MWC & 4.3 \\
\hline CWC & 10.2 & $\mathrm{NCP}$ & 5.6 & $\mathrm{AH}$ & 14.9 & $\mathrm{~N} / \mathrm{CP}$ & 4.3 \\
\hline STP & 10.2 & $\mathrm{pH}$ & 5.6 & SOM & 14.8 & $\mathrm{NCP}$ & 3.9 \\
\hline SAP & 9.9 & $\stackrel{1}{\mathrm{C}} / \mathrm{N}$ & 5.4 & AK & 10.9 & STP & 3.8 \\
\hline SVMC & 8.8 & SWC & 4.9 & SBD & 8.1 & SWC & 3.7 \\
\hline $\mathrm{AH}$ & 8.8 & SOM & 4.7 & TK & 7.4 & SVMC & 3.5 \\
\hline SOC & 8.6 & $\mathrm{TN}$ & 4.0 & $\mathrm{HN}$ & 7.2 & SAP & 2.8 \\
\hline
\end{tabular}

Abbreviations: Climate factors: light intensity—LI, air temperature-AT, relative humidity above the surface of $1.5 \mathrm{~m}-\mathrm{AH}$, soil surface temperature-ST0, soil temperature below the surface $5 \mathrm{~cm}-\mathrm{ST}$, soil temperature below the surface $10 \mathrm{~cm}-\mathrm{ST} 10$, soil water content-SWC. Soil properties: soil bulk density-SBD, soil water mass content-SWMC, soil volumetric moisture content-SVMC, maximum moisture capacity-MMC, capillary water capacity $-\mathrm{CWC}$, minimum water-holding capacity-MWC, non-capillary porosity $-\mathrm{NCP}$, capillary porosity $-\mathrm{CP}$, soil total porosity $-\mathrm{STP}$, soil aeration porosity $-\mathrm{SAP}, \mathrm{pH}$ value $-\mathrm{pH}$, total nitrogen $-\mathrm{TN}$, hydrolysable nitrogen-HN, total phosphorus-TP, available phosphorus-AP, total potassium-TK, available potassium-AK, soil organic matter-SOM, soil organic carbon-SOC, and $\mathrm{C} / \mathrm{N}$ ratio.

\subsection{The Coupling Relationship Between Plant Species and the Microenvironment}

The optimal combination of explanatory variables in the environmental factors is shown in Table 4, by gradually adding each explanatory variable from high to low. The best combinations of explanatory variables in the environmental factors of forest gaps and non-gaps were different. We added every factor from high to low in order to select the main factors that influence the composition of the regeneration layer. The ST10 was the highest explanation rate among those factors in the forest gaps and non-gaps. Moreover, the explanation rate of ST10 of non-gaps was 33.7\%, indicated that ST10 may be the critical factor deciding the species distribution of non-gaps. The explanatory variables that forest gaps and non-gaps both had in common were the variables: ST10, ST5, HN, C/N, and MWC. The differentiating explanatory variables in the forest gaps were LI, SAP, TP, AH, and NCP, whilst in the non-gaps the variables were AT, TN, AK, AP, and SOC.

The DCCA ordination axis cumulative contribution rate was calculated between the environmental factors and the plant species in the regeneration layer of the forest gaps and non-gaps using selected environmental factors. The factors included ST10, LI, ST5, HN, SAP, C/N, TP, AH, $\mathrm{NCP}$, and MWC in the forest gaps, and ST10, AT, TN, HN, AK, AP, ST5, MWC, C/N, and SOC in the non-gaps (Table 4). 
The correlation coefficients between the first and second axis of the plant species in the regeneration layer and the environmental factors in the forest gaps and non-gaps were relatively high (Table 5). This indicated the reliability of using the DCCA method in the interpretation of the relationship between the main species of regeneration in the forest gaps, non-gaps and the environment. The explanation rate of factors that were chosen in the forest gaps was $57.31 \%$, with the first axis and second axis accounting for $40.39 \%$ and $16.92 \%$, respectively. The precision of the interpretation was 0.02 , which showed a significant difference. Meanwhile, the explanation rate of factors that were chose in the non-gaps was $62.4 \%$, with the first axis and second axis accounting for $45.32 \%$ and $17.08 \%$, respectively . The precision of the interpretation was 0.012 , which showed a significant difference and had a credible analysis.

Table 4. The explanation rate of main micro-environmental factors in the forest gaps and non-gaps.

\begin{tabular}{ccccc}
\hline Gap & Explains $\%$ & & Non-Gap & Explains \% \\
\cline { 1 - 2 } \cline { 5 - 5 } ST10 & 16.2 & & ST10 & 33.7 \\
LI & 12.7 & & AT & 10.8 \\
ST5 & 12.5 & & TN & 7.7 \\
HN & 12.2 & & HN & 7.5 \\
SAP & 12.6 & & AK & 6.9 \\
C/N & 9.1 & & AP & 10.4 \\
TP & 9.8 & & ST5 & 6.9 \\
AH & 5.3 & & MWC & 4.7 \\
NCP & 4.6 & & C/N & 5.9 \\
MWC & 4.1 & & SOC & 2.9 \\
\hline
\end{tabular}

Abbreviations: Climate factors: light intensity-LI, air temperature-AT, relative humidity above the surface of $1.5 \mathrm{~m}-\mathrm{AH}$, soil temperature below the surface $5 \mathrm{~cm}-\mathrm{ST} 5$, soil temperature below the surface $10 \mathrm{~cm}-\mathrm{ST} 10$. Soil properties: minimum water-holding capacity $-\mathrm{MWC}$, non-capillary porosity $-\mathrm{NCP}$, soil aeration porosity-SAP, total nitrogen- $\mathrm{TN}$, hydrolysable nitrogen- $\mathrm{HN}$, total phosphorus-TP, available phosphorus- $\mathrm{AP}$, available potassium-AK, soil organic carbon-SOC, and $\mathrm{C} / \mathrm{N}$ ratio.

Table 5. The detrended canonical correspondence analysis (DCCA) ordination axis cumulative contribution rate of plant species in the regeneration layer of forest gaps and non-gaps.

\begin{tabular}{cccccccccc}
\hline & \multicolumn{4}{c}{ Gap } & \multicolumn{4}{c}{ Non-Gap } \\
\hline & Axis 1 & Axis 2 & Axis 3 & Axis 4 & Axis 1 & Axis 2 & Axis 3 & Axis 4 \\
Eigenvalues & 0.1413 & 0.0592 & 0.0482 & 0.0139 & 0.1314 & 0.0495 & 0.0299 & 0.0119 \\
Cumulative percentage variance of & 40.16 & 56.98 & 70.68 & 74.64 & 44.07 & 60.67 & 70.71 & 74.7 \\
species data & 0.9987 & 0.9985 & 0 & 0 & 0.9996 & 0.9984 & 0 & 0 \\
Species-environment correlations & 40.39 & 57.31 & & & 45.32 & 62.4 & & \\
Cumulative percentage variance (\%) & 40.45 &
\end{tabular}

The coupling relationship values between the main species in the regeneration layer and the environmental factors in the forest gaps and non-gaps were calculated. These relationship values were measured by the length of the factors multiplied by the cosine of the angle between the species and factors as shown in Figures 2 and 3. Then the extent of the environmental factors' impact on the main species could be measured (Tables 6 and 7). In the forest gaps, the environmental factors LI, ST5, ST10, $\mathrm{AH}$, and SAP had strong impacts on each species, whilst the influence of other factors was not obvious. Meanwhile, the strong impacts of the factors C/N, AP, ST5, AT, ST10, and SOC on each species were detected. For each factor, there was a positive or negative effect on each species in the forest gaps and non-gaps. 


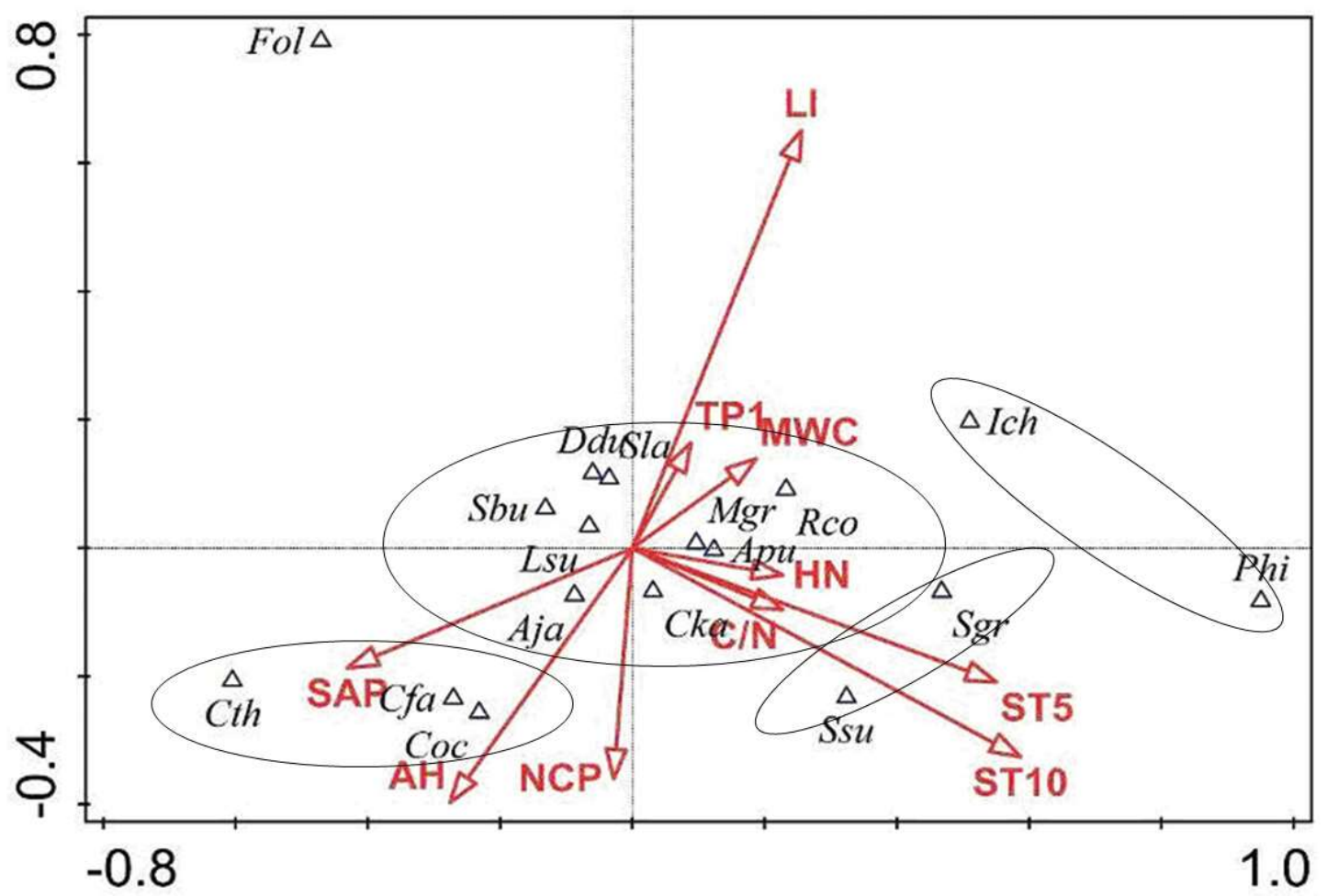

Figure 2. DCCA ordination of the main species in the regeneration layer of the forest gaps.

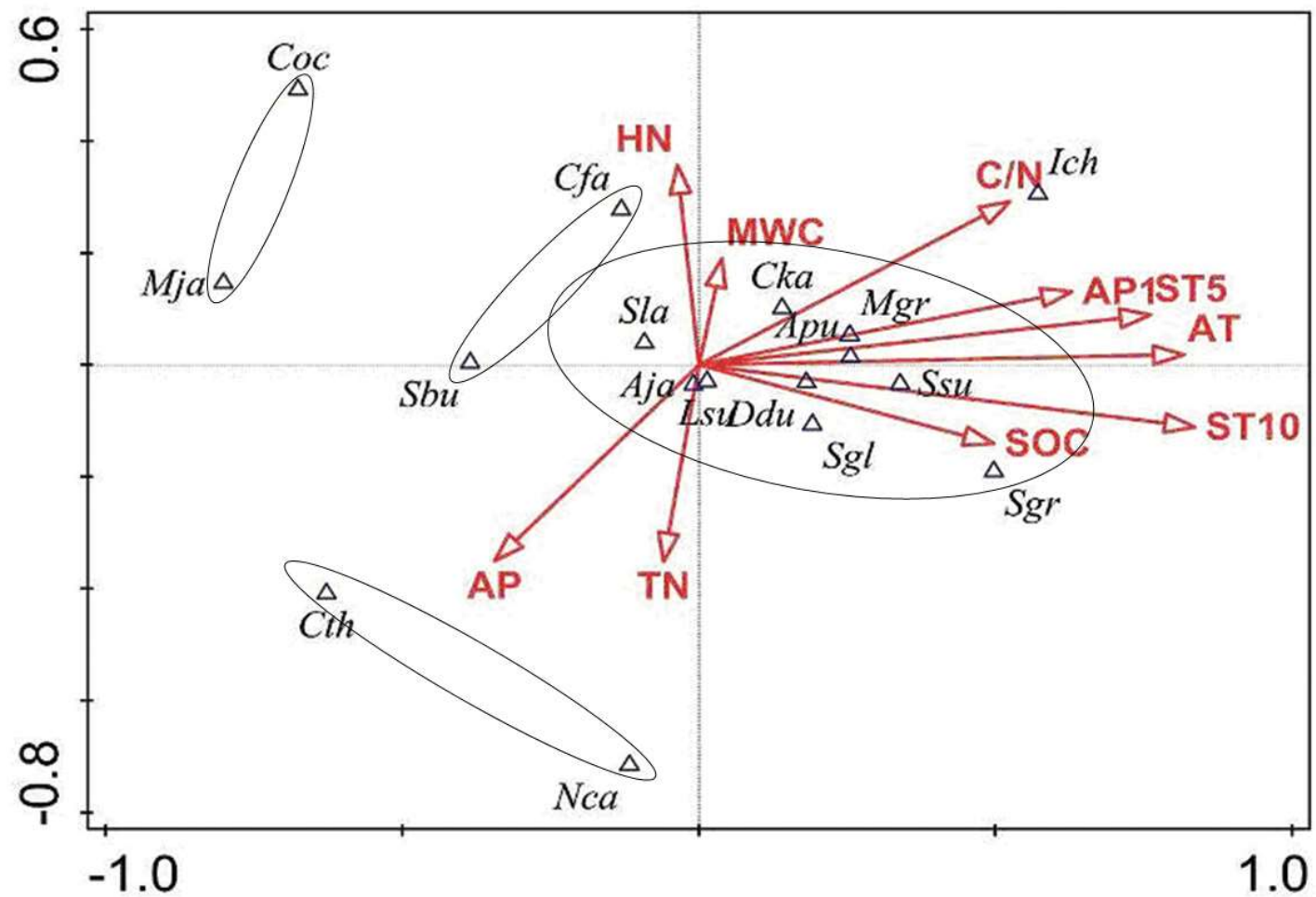

Figure 3. DCCA ordination of the main species in the regeneration layer of the non-gaps. 
Table 6. Quantitative relationship between main species in the regeneration layer and micro-environmental factors in the forest gaps.

\begin{tabular}{ccccccccccc}
\hline & LI & TP & MWC & HN & C/N & ST5 & ST10 & NCP & AH & SAP \\
\hline Aja & $-8.52 \boldsymbol{\nabla}$ & -2.44 & -3.19 & -2.01 & -1.53 & -3.88 & -3.11 & 3.46 & $6.38 \bullet$ & $6.12 \bullet$ \\
Apu & 3.28 & 1.3 & 2.52 & 3.16 & 3.15 & $7.54 \bullet$ & $8.03 \bullet$ & -0.3 & $-3.64 \boldsymbol{\nabla}$ & $-5.82 \boldsymbol{\nabla}$ \\
Cfa & $-8.48 \boldsymbol{\nabla}$ & -2.43 & -3.19 & -2.01 & -1.54 & -3.82 & -3.11 & 3.49 & $6.39 \bullet$ & $6.12 \bullet$ \\
Cka & $-6.67 \boldsymbol{\nabla}$ & -1.55 & -0.67 & 1.84 & 2.53 & $5.71 \bullet$ & $7.36 \bullet$ & 4.26 & 3.2 & -0.17 \\
Coc & $-8.96 \boldsymbol{\nabla}$ & -2.52 & 3.14 & 1.65 & 1.11 & 2.93 & 2.05 & 3.89 & $6.54 \bullet$ & $5.82 \bullet$ \\
Cth & $-6.17 \boldsymbol{\nabla}$ & -1.79 & -3.04 & -2.77 & -2.53 & $-6.17 \boldsymbol{\nabla}$ & $-6.09 \boldsymbol{\nabla}$ & 1.95 & $5.31 \bullet$ & $6.38 \bullet$ \\
Ddu & $6.42 \bullet$ & 1.49 & 0.56 & -1.93 & -2.6 & $-5.85 \boldsymbol{\nabla}$ & $-7.5 \boldsymbol{\nabla}$ & -4.2 & -3.15 & 0.33 \\
Fol & $5.91 \bullet$ & 1.3 & 0.06 & -2.1 & -2.75 & $-6.26 \boldsymbol{\nabla}$ & $-7.88 \boldsymbol{\nabla}$ & 0.6 & -2.79 & $-5.24 \boldsymbol{\nabla}$ \\
Ich & $6.42 \bullet$ & 1.98 & 3.08 & 2.73 & 2.43 & $5.95 \bullet$ & $5.79 \bullet$ & -2.52 & $-5.09 \boldsymbol{\nabla}$ & $-6.39 \boldsymbol{\nabla}$ \\
Lsu & 0.17 & -0.05 & -1.4 & -3.06 & -3.39 & $-7.95 \boldsymbol{\nabla}$ & $-9.09 \boldsymbol{\nabla}$ & -1.88 & 0.86 & 4.07 \\
Mgr & 4.13 & 1.42 & 2.7 & 3.09 & 3 & $7.22 \bullet$ & $7.59 \bullet$ & -0.77 & $-4.2 \boldsymbol{\nabla}$ & $-6.05 \boldsymbol{\nabla}$ \\
Phi & 2.65 & 1.06 & 2.38 & 3.18 & 3.22 & $7.69 \bullet$ & $8.28 \bullet$ & 0 & -3.3 & $-5.7 \boldsymbol{\nabla}$ \\
Rco & $6.55 \bullet$ & 2.02 & 3.09 & 2.68 & 2.4 & $5.9 \bullet$ & $5.73 \bullet$ & -2.52 & $-5.5 \boldsymbol{\nabla}$ & $-6.4 \boldsymbol{\nabla}$ \\
Sbu & 0.75 & -0.14 & -1.45 & -3.08 & -3.4 & $-7.96 \boldsymbol{\nabla}$ & $-9.09 \boldsymbol{\nabla}$ & -1.76 & 1.03 & 4.2 \\
Sgr & 2 & 0.91 & 2.26 & 3.2 & 3.28 & $7.8 \bullet$ & $8.5 \bullet$ & 0.3 & -2.94 & $-5.46 \boldsymbol{\nabla}$ \\
Sla & $7.41 \bullet$ & 1.79 & 1.04 & -1.55 & -2.23 & $-4.98 \boldsymbol{\nabla}$ & $-6.66 \boldsymbol{\nabla}$ & -4.51 & -3.97 & -0.56 \\
Ssu & -2.484 & -0.3169 & 0.9355 & 2.9001 & 3.3168 & $7.727 \bullet$ & $9.0415 \bullet$ & 2.5236 & 0.11518 & -3.296 \\
\hline
\end{tabular}

Note: $\bullet$ represents a high positive effect between species and environmental factors, $\boldsymbol{\nabla}$ represents a high negative effect between species and environmental factors, the same below.

Table 7. The quantitative relationship between main species in the regeneration layer and micro-environmental factors in the non-gaps.

\begin{tabular}{|c|c|c|c|c|c|c|c|c|c|c|}
\hline & HN & MWC & $\mathrm{C} / \mathrm{N}$ & AP & ST5 & AT & ST10 & SOC & TN & AK \\
\hline $\mathrm{Sgl}$ & -2.466 & 0.711 & 3.7083 & $5.8113 \bullet$ & $7.443 \bullet$ & $8.4002 \bullet$ & $9.3972 \bullet$ & $6.0411 \bullet$ & 1.470687 & -1.527 \\
\hline Sbu & 0.524 & -0.439 & $-6.204 \boldsymbol{\nabla}$ & $-7.503 \boldsymbol{\nabla}$ & $-9.11 \boldsymbol{\nabla}$ & $-9.791 \mathbf{\nabla}$ & $-10.02 \boldsymbol{\nabla}$ & $-5.989 \boldsymbol{\nabla}$ & 0.672668 & 4.0985 \\
\hline Mja & 1.1852 & -0.04 & $-5.595 \mathbf{\nabla}$ & $-7.164 \boldsymbol{\nabla}$ & $-8.821 \boldsymbol{\nabla}$ & $-9.62 \nabla$ & $-10.09 \nabla$ & $-6.166 \boldsymbol{\nabla}$ & $2.63 \times 10^{-16}$ & 3.3418 \\
\hline Cka & 1.4354 & 1.3842 & $7.0677 \bullet$ & $7.0614 \bullet$ & $8.0851 \bullet$ & $8.1246 \bullet$ & $7.3867 \bullet$ & 3.9018 & -3.04056 & $-5.81 \boldsymbol{\nabla}$ \\
\hline Ddu & -1.113 & 0.0803 & $5.6737 \bullet$ & $7.1886 \bullet$ & $8.8436 \bullet$ & $9.6359 \bullet$ & $10.097 \bullet$ & $6.1601 \bullet$ & $2.63 \times 10^{-16}$ & -3.426 \\
\hline Sla & 2.15 & 4782 & -4.383 & $-6.307 \boldsymbol{\nabla}$ & $-7.967 \boldsymbol{\nabla}$ & $-9.209 \boldsymbol{\nabla}$ & $-9.709 \boldsymbol{\nabla}$ & $-6.147 \boldsymbol{\nabla}$ & -1.04026 & 2.1624 \\
\hline Lsu & & & & 1.27 & & & & & & 3997 \\
\hline Mgr & & & 6.885 & $7.7 \bullet$ & 9.16 & & 9.5207• & & -1.5 & -4.891 \\
\hline Ich & 1.6455 & 1.4784 & $7.1989 \bullet$ & 7.4017• & $8.5889 \bullet$ & $8.7704 \bullet$ & $8.2226 \bullet$ & 4.4599 & -2.61767 & $-5.627 \boldsymbol{\nabla}$ \\
\hline $\mathrm{Coc}$ & 3.1448 & 0.9538 & -2.986 & $-5.102 \boldsymbol{\nabla}$ & $-6.728 \boldsymbol{\nabla}$ & $-7.723 \mathbf{\nabla}$ & $-8.834 \boldsymbol{\nabla}$ & $-5.807 \boldsymbol{\nabla}$ & -1.91865 & 0.8721 \\
\hline Cth & -1.919 & -1.723 & $-7.187 \boldsymbol{\nabla}$ & $-7.189 \boldsymbol{\nabla}$ & $-8.269 \boldsymbol{\nabla}$ & $-8.356 \mathbf{\nabla}$ & $-7.68 \boldsymbol{\nabla}$ & -4.068 & 2.932 & $5.7601 \bullet$ \\
\hline Ssu & -0.931 & & $6.2037 \bullet$ & $7.3231 \bullet$ & $8.9819 \bullet$ & $9.7162 \bullet$ & $10.094 \bullet$ & $6.1058 \bullet$ & -0.29995 & -3.673 \\
\hline $\mathrm{Cfa}$ & 4.0407 & 1.8369 & 0.4395 & -1.863 & -2.995 & -4.064 & $-5.575 \boldsymbol{\nabla}$ & -4.149 & -3.5007 & -1.969 \\
\hline Aja & -3.913 & -2.278 & $-5.266 \nabla$ & -3.85 & -3.815 & -3.1 & -1.754 & -0.2 & 4.252768 & $5.2801 \bullet$ \\
\hline Nca & & & -4 & -2 & & & & & & 4.8033 \\
\hline Sgr & & & & $6.4578 \bullet$ & $8.1605 \bullet$ & & $9.7783 \bullet$ & $6.1764 \bullet$ & 0.820479 & -2.447 \\
\hline $\mathrm{Apu}$ & -0.188 & 0.5369 & $6.4713 \bullet$ & $7.6154 \bullet$ & $9.1828 \bullet$ & $9.794 \bullet$ & 9.9144• & $5.8622 \bullet$ & -1.00382 & -4.385 \\
\hline
\end{tabular}

\section{Discussion}

\subsection{The Dominant Species in the Regeneration Layer of the Forest Gaps and Non-Gaps}

There was a high proportion of individual species and densities that occupied the dominance position in the forest, and this suggested better regeneration [26]. Importance values could be calculated after measurement of the density, diameter at breast height (DBH), and the number of individual species. The importance value of the L. subcoriacea species was the highest in the forest gaps and non-gaps, which indicated that L. subcoriacea had taken full advantage of the environmental factors and it had better adaptation ability. Therefore, the species will play an important role in forest regeneration. Microenvironment heterogeneity in the forest gaps promoted tree growth and regeneration [3]. The 
importance values of C. kawakamii, S. lancifolia, and Calamus thysanolepis in the forest gaps were relatively higher than those in the non-gaps. Meanwhile, the forest gap limited the biomass allocation and regeneration of shade tolerant species [27], including Itea chinensis var oblonga, C. octopetala, and C. thysanolepis in the forest gaps.

Species competition and forest cover are important factors in determining forest regeneration [28]. The main species that we selected were species that had relative high competition intensities with C. kawakamii [4,18]. Meanwhile, these species occupied a high position in the community of this natural forest [18]. The competition ability of C. kawakamii in the forest gaps was higher than that in the non-gaps [4]. Moreover, the regeneration niche width of C. kawakamii was higher than that in the non-gaps [5]. Therefore, C. kawakamii seedlings in the forest gaps had a better regeneration situation, thereby promoting the sprout regeneration of dominant tree species in the forest gaps [29].

\subsection{The Impact of Environmental Factors to the Species Coexistence in the Forest Gaps and Non-Gaps}

The forest gap is a complicated interaction between stand structure, soil, and microclimatic interactions [30]. The microenvironment heterogeneity of forest gaps determines the explanation rate of environmental factors, with no obvious difference in the term of each explanation rate. The different explanation rates for environmental factors in the forest gaps illustrated the environmental heterogeneity [1,6,31]. However, some factors, like forest stand, terrain, climatic, and soil properties, have been the main factors in the determination of species distribution [15]. Thus, the explanation rates of some environmental factors in the non-gaps played a decisive role with a relatively high explanation rate, whilst the explanation rates of other factors were relatively low. Tree species, through adaptation to environmental conditions and mutual competition, could achieve coexistence and ensure species diversity in the non-gaps [32].

Light intensity was directly increasing after the formation of the forest gap, and it changed the temperature and humidity in the local environment, and it also affected the physicochemical properties of the soil and species distribution in the regeneration layer [3,6]. Microbial metabolic activity was enhanced with the improvement of light intensity and air temperature, which could accelerate the conversion of TP into AP. This would increase the concentration of AP and promote plant absorption of more AP from the soil [33]. However, the limitation of TP restrained the increase of AP, and it became a limiting factor affecting plant growth. With a high metabolism and evaporation rate for pioneer species in the forest gaps, high humidity restricted transpiration. This led to screening environmental factors affecting the plant species in the regeneration layer that were different. Meanwhile, with a relatively low light intensity, air temperature, and microbe metabolism in the non-gaps, the substantial decomposition of various types of animal and plant residues, plant litters, and wastes was difficult, which led to soil organic matter content that was rich, but could not be decomposed quickly into nutrients that plants could utilize directly [34]. Therefore, tree species experienced a decline in growth due to insufficient AP and TK and a difficult to reach canopy layer of the forest.

\subsection{The Relationships Between Species Distribution and Micro-Environment in the Forest Gaps and Non-Gaps}

The explanation rates of environmental factors to the species distribution in the regeneration layer of the forest gaps and non-gaps were $57.31 \%$ and $62.4 \%$, respectively, where both conformed to the theory of ecological niche differentiation, which explains that different species adapt to different habitats and are restricted by various habitat factors. Plant species can coexistence by inhabiting different resources though space and time. This is described as the theory of ecological niche differentiation and it plays a vital role during the stage of community succession and plant regeneration under changing environmental factors [35,36]. In general, the microclimate changes after the formation of a forest gap, such as improvements in solar radiation, temperature, and humidity, and then it affects nutrient cycling and microbial activity [6]. The relationship between C. kawakamii and other species taking advantage of resources showed an obvious sharing trend as a result of the heterogeneity of the forest gap microenvironment, which promoted species coexistence [3]. However, the niche overlaps 
of C. kawakamii and S. superba, and O. xylocarpa, and Vaccinium carlesii were relatively high in the regeneration layer of the non-gaps. This demonstrated a strong competition amongst these species pairs; therefore, the community moved towards species diversification in the non-gaps [5], which needed to take some measures to protect C. kawakamii species regeneration.

\subsection{Implications for the Regeneration of the C. kawakamii Population}

According to the quantitative relationship between the species and the environment, we could provide some specific measures that protect our target species of C. kawakamii by restricting or developing some environmental factors. The light intensity in the forest gaps was higher in comparison to the non-gaps, which directly and indirectly affected other factors [6]. Under natural conditions, LI, ST5, ST10, AH, and SAP are difficult to control. We could implement artificial management operations, including the creation of artificial gaps, adequate fertilization, or other activities that could lead to better regeneration of $C$. kawakamii species. The medium gap has better environment heterogeneity and soil nutrition release during the process of litter decomposition [6,37]. Therefore, creating an artificial forest gap could improve solar radiation, light intensity, and air temperature, thus improving plant growth in the regeneration layer of the non-gaps. Compared to the environmental factors that influenced species growth in the non-gaps, plant species had a high demand for nutrition, such as $\mathrm{AP}$, SOC, and HN. Proper fertilization could promote absorption in plant nutritional organs, which could be beneficial to species regeneration in the non-gaps. However, additional fertilization is not required in forest gaps.

\section{Conclusions}

The environmental factors had a varied influence on the distribution patterns of the main species in the regeneration layer of the forest gaps and non-gaps. Species distribution patterns in the forest gaps were determined by the comprehensive function of microenvironment factors due to gap heterogeneity. However, some environmental factors in the non-gaps played a decisive role in the tree species distribution pattern. The relationship between the tree species distribution pattern and the microenvironment factors adjusted to the ecological niche hypothesis. Finally, some specific measures were suggested to protect the C. kawakamii species. This could provide a scientific basis for the regeneration and reconstruction of the endangered C. kawakamii population.

Author Contributions: Data curation, L.J.; Formal analysis, Z.H. and W.H.; Investigation, Z.H, L.W., Z.W. and D.X.; Methodology, Z.H. and J.L.; Writing-original draft, Z.H, L.W.

Funding: This research was funded by the National Natural Science Foundation of China (NSFC), grant number 31700550 and 31770678; Science and Technology Promotion of Project Forestry Bureau of Fujian Province, grant number 2018TG14-2.

Acknowledgments: We wish to express our thanks for the support received from the Castanopsis kawakamii Nature Reserve in Sanming City, Fujian Province to allow us to collect samples. The authors would like to thank Daliang $\mathrm{Fu}$, Jie Niu and Yingxing Shi, as well as Shan Lin and Yijun Lin in the field work. We also do appreciate Ph.D candidate Michael V. Lambert in the University of Alabama for the encouragement, helpful discussions and valuable suggestions during the revision of this manuscript. The authors also record sincere appreciation for helpful and constructive comments made by reviewers of the draft manuscript.

Conflicts of Interest: The authors declare no conflicts of interest.

\section{References}

1. Muscolo, A.; Bagnato, S.; Sidari, M.; Mercurio, R. A review of the roles of forest canopy gaps. J. For. Res. 2014, 25, 725-736. [CrossRef]

2. Zang, R.G.; Liu, G.Y. Gap dynamic and forest biodiversity; China Forestry Publish Press: Beijing, China, 1999.

3. He, Z.S.; Liu, J.F.; Wu, C.T.; Zheng, S.Q.; Hong, W.; Su, S.J.; Wu, C.Z. Effects of forest gaps on some microclimate variables in Castanopsis kawakamii natural forest. J. Mt. Sci. 2012, 9, 706-714. [CrossRef]

4. He, Z.S.; Liu, J.F.; Su, S.J.; Zheng, S.Q.; Xu, D.W.; Wu, Z.Y.; Hong, W.; Wang, J.L. Effects of forest gaps on soil properties in Castanopsis kawakamii nature forest. PLoS ONE 2015, 10, e141203. [CrossRef] [PubMed] 
5. Masaki, T.; Osumi, K.; Takahashi, K.; Hoshizaki, K.; Matsune, K.; Suzuki, W. Effects of microenvironmental heterogeneity on the seed-to-seedling process and tree coexistence in a riparian forest. Ecol. Res. 2007, 22, 724-734. [CrossRef]

6. Schliemann, S.A.; Bockheim, J.G. Methods for studying treefall gaps: A review. For. Ecol. Manag. 2011, 261, 1143-1151. [CrossRef]

7. Kirchner, K.; Kammermeier, S.; Bruelheide, H. The response of the pseudoannual species Trientalis europaea L. to forest gap dynamics in a near-natural spruce forest. For. Ecol. Manag. 2008, 257, 1070-1077. [CrossRef]

8. Liao, J.B.; Bogaert, J.; Nijs, I. Species interactions determine the spatial mortality patterns emerging in plant communities after extreme events. Sci. Rep. 2015, 5, 11229. [CrossRef]

9. Chen, L.; Liu, G.H.; Liu, D. How forest gap and elevation shaped Abies faxoniana Rehd. et Wils. regeneration in a Subalpine coniferous forest, Southwestern China. Forests 2018, 9, 271. [CrossRef]

10. Thorson, J.T.; Ianelli, J.N.; Larsen, E.A.; Ries, L.; Scheuerell, M.D.; Szuwalski, C.; Zipkin, E.F. Joint dynamic species distribution models: A tool for community ordination and spatio-temporal monitoring. Glob. Ecol. Biogeogr. 2016, 25, 1144-1158. [CrossRef]

11. Kent, M. Vegetation Description and Data Analysis: A Practical Approach; John Wiley and Sons: Hoboken, NJ, USA, 2012.

12. Veneklaas, E.J.; Fajardo, A.; Lozano, J. Gallery forest types and their environmental correlates in a Colombian savanna landscape. Ecography 2005, 28, 236-252. [CrossRef]

13. Kargar-Chigani, H.; Javadi, S.; Zahedi-Amiri, G.; Khajeddin, S.; Jafari, M. Vegetation composition differentiation and species-environment relationships in the northern part of Isfahan Province, Iran. J. Arid Land 2017, 9, 161-175. [CrossRef]

14. Sarvade, S.; Gupta, B.; Singh, M. Composition, diversity and distribution of tree species in response to changing soil properties with increasing distance from water source-A case study of Gobind Sagar reservoir in India. J. Mt. Sci. 2016, 13, 522-533. [CrossRef]

15. Du, H.; Peng, W.X.; Song, T.Q.; Zeng, F.P.; Wang, K.L.; Song, M.; Zhang, H. Spatial pattern of woody plants and their environmental interpretation in the karst forest of southwest China. Plant Biosyst. 2013, 149, 1-10. [CrossRef]

16. Liu, J.; Hong, W.; Li, J.; Yang, W. Gap natural disturbance regime in the Castanopsis kawakamii forest. Acta Ecol. Sinica 2003, 23, 1991-1999.

17. Liu, J.F.; He, Z.S.; Hong, W.; Zheng, S.Q.; Wang, Z.J. Conservation ecology of endangered plant Castanopsis kawakamii. J. Beijing Univ. 2011, 33, 136-143.

18. He, Z.S.; Liu, J.F.; Zheng, S.Q.; Hong, W.; Wu, C.Z.; Wu, Z.Y.; Niu, J.; Lin, Y.J. Studies on the seeds dispersal and seedlings regeneration in gaps and understory of Castanopsis kawakamii natural forest. J. Trop. Subtrop. Bot. 2011, 19, 230-236. [CrossRef]

19. Buajan, S.; Liu, J.F.; He, Z.S.; Feng, X.P. Effect of gap sizes on specific leaf area and chlorophyll contents at the Castanopsis kawakamii natural reserve forest, China. Forests 2018, 9, 682. [CrossRef]

20. Hilborn, R.; Mangel, M. The Ecological Detective: Confronting Models with Data; Princeton University Press: Princeton, NJ, USA, 1997.

21. Zhang, W.R.; Yang, G.Y.; Tu, X.N. Forest Soil Analysis Method; China Forestry Publish Press: Beijing, China, 1999.

22. Braak, C.J.F. Canonical correspondence-analysis-A new eigenvector technique for multivariate direct gradient analysis. Ecology 1986, 67, 1167-1179. [CrossRef]

23. Braak, C.J.F.; Barendregt, L.G. Weighted averaging of species indicator values-Its efficiency in environmental calibration. Math. Biosci. 1986, 78, 57-72. [CrossRef]

24. Šmilauer, P.; Lepš, J. Multivariate Analysis of Ecological Data Using CANOCO 5; Cambridge University Press: Cambridge, UK, 2014.

25. Braak, C.J.F.; Smilauer, P. CANOCO Reference Manual and User's Guide: Software for Ordination (Version 5.0); Microcomputer Power: Ithaca, NY, USA, 2012.

26. Tesfaye, G.; Teketay, D.; Fetene, M.; Beck, E. Regeneration of seven indigenous tree species in a dry Afromontane forest, Southern Ethiopia. Flora-Morphol. Distrib. Funct. Ecol. Plants 2010, 205, 135-143. [CrossRef] 
27. Lu, D.L.; Wang, G.G.; Yan, Q.L.; Gao, T.; Zhu, J.J. Effects of gap size and within-gap position on seedling growth and biomass allocation: Is the gap partitioning hypothesis applicable to the temperate secondary forest ecosystems in Northeast China? For. Ecol. Manag. 2018, 429, 351-362. [CrossRef]

28. Donoso, P.J. Crown Index: A canopy balance indicator to assess growth and regeneration in uneven-aged forest stands of the coastal range of Chile. Forestry 2005, 78, 337-351. [CrossRef]

29. Zhang, T.; Yan, Q.L.; Wang, J.; Zhu, J.J. Restoring temperate secondary forests by promoting sprout regeneration: Effects of gap size and within-gap position on the photosynthesis and growth of stump sprouts with contrasting shade tolerance. For. Ecol. Manag. 2018, 429, 267-277. [CrossRef]

30. Madsen, P.; Hahn, K. Natural regeneration in a beech-dominated forest managed by close-to-nature principles-a gap cutting based experiment. Can. J. For. Res. 2008, 38, 1716-1729. [CrossRef]

31. Zhu, J.J.; Lu, D.L.; Zhang, W.D. Effects of gaps on regeneration of woody plants: A meta-analysis. J. For. Res. 2014, 25, 501-510. [CrossRef]

32. Bottero, A.; Garbarino, M.; Dukic, V.; Govedar, Z.; Lingua, E.; Nagel T, A.; Motta, R. Gap-phase dynamics in the old-growth forest of Lom, Bosnia and Herzegovina. Silva Fennica 2011, 45, 875-887. [CrossRef]

33. Liu, Y.; Zhang, J.; Yang, W.Q.; Wu, F.Z.; Xu, Z.F.; Tan, B.; Zhang, L.; He, X.H.; Guo, L. Canopy gaps accelerate soil organic carbon retention by soil microbial biomass in the organic horizon in a subalpine fir forest. Appl. Soil Ecol. 2018, 125, 169-176. [CrossRef]

34. Haghverdi, K.; Kiadaliri, H.; Sagheb-Talebi K, Y.; Kooch, Y. Variability of plant diversity and soil features following gap creation in Caspian beech forests of Iran. Ann. Biol. Res. 2012, 3, 4622-4635.

35. Brown, C.; Burslem, D.F.; Illian, J.B.; Bao, L.; Brockelman, W.; Cao, M.; Chang, L.W.; Dattaraja, H.S.; Davies, S.; Gunatilleke, C.V.; et al. Multispecies coexistence of trees in tropical forests: Spatial signals of topographic niche differentiation increase with environmental heterogeneity. Proc. Biol. Sci. 2013, 280, 20130502. [CrossRef]

36. Edwards, R.D.; Crisp, M.D.; Cook, L.G. Niche differentiation and spatial partitioning in the evolution of two Australian monsoon tropical tree species. J. Biogeogr. 2013, 40, 559-569. [CrossRef]

37. Zhang, Q.; Zak, J.C. Effects of gap size on litter decomposition and microbial activity in a subtropical forest. Ecology 1995, 76, 2196-2204. [CrossRef]

(C) 2019 by the authors. Licensee MDPI, Basel, Switzerland. This article is an open access article distributed under the terms and conditions of the Creative Commons Attribution (CC BY) license (http:/ / creativecommons.org/licenses/by/4.0/). 